\title{
Nausea and vomiting
}

\author{
GT Linklater \\ Consultant in Palliative Medicine, Department of Palliative Medicine, Aberdeen Royal Infirmary, Aberdeen, UK
}

\section{OVERVIEW}

\section{First principles}

- Symptoms are best controlled if the underlying cause for the symptom can be identified and treated or removed.

- In advanced life-limiting illness it may not be possible or appropriate to identify the underlying cause of a symptom or to treat the cause if found. In these circumstances a 'palliative' treatment is indicated.

- All recommendations in this paper relate to the treatment of patients with advanced life-limiting illness.

KEYWORDS life-limiting illness, nausea, vomiting

DECLARATION OF INTERESTS No conflict of interests declared.
Correspondence to GT Linklater Department of Palliative Medicine Roxburghe House Ashgrove Road

Aberdeen AB25 2ZH

UK

e-mail g.linklater@nhs.net

\section{INTRODUCTION}

Nausea is an unpleasant symptom that diminishes quality of life. It may or may not be associated with vomiting. There are very many potential causes of nausea in patients with advanced life-limiting disease and a large number of medications that can be used as anti-emetics. This often leads to confusion about how best to manage nausea at the end of life. An understanding of the physiology of nausea and a careful history can help direct treatment more effectively.

\section{PHYSIOLOGY}

Imagine a caveman. He is very hungry. His spear snapped when hunting a baby woolly rhinoceros and a sabre-toothed tiger chased him away from a hopeful looking carcass. He passes a bush with lovely looking red berries. Chomp, chomp, yum, yum. But wait, something is wrong. A wave of nausea surfs over him. Maybe they were the ones his mother had told him not to eat?

Let's look inside our caveman. His small bowel is retroperistalsing, his stomach has stopped contracting, and his lower oesophageal sphincter is relaxed. He is no longer secreting gastric acid. His mouth begins to fill with (alkaline) saliva. And then with a big heave his stomach contents are transformed into a cascade of vomit.

Our caveman lives to forage another day. His story illustrates a couple of important points. Nausea (and vomiting) is a powerful survival reflex, reducing the digestion and absorption of ingested 'poison'. Notably, the normal absorption of oral medications (including anti-emetics) may be significantly reduced in the presence of nausea, even in the absence of vomiting. Nausea also protects the upper gastrointestinal tract from the corrosive effects of expelled gastric acid (cf. bulimia, where pitted teeth are evidence of vomiting without preceding nausea).

\section{HISTORY (THREE TYPES OF NAUSEA)}

The patient's history and a knowledge of the underlying pathophysiology can help anti-emetic choice.

I. You know what doctor? I feel sick all the time. It doesn't matter if I eat or don't eat, if I am sick or if I am not sick

The chemoreceptor trigger zone (CTZ) is found in the medulla. It lies outside the blood-brain barrier so is 'bathed' in circulating drugs and toxins. As blood flow is uninterrupted, the nausea generated here is typically constant. The major neurotransmitters involved are dopamine $\left(\mathrm{D}_{2}\right)$ and serotonin $\left(5-\mathrm{HT}_{3}\right)$.

2. It's funny doctor. I feel fine when I order my lunch, but when I get the first whiff of the food it just turns my stomach. When it is put in front of me I just can't face it, I can hardly look at it, and they have to take it away.

The vomiting centre (VC) is an aggregation of afferent 
and efferent nuclei in the medulla. These nuclei receive inputs from a variety of sources including the CTZ, higher cerebral centres (fear, sights, smells, etc.), vestibulocochlear nerve (motion sickness), glossopharyngeal nerve (tickle the back of your throat and find out what happens), and vagal nerve (myocardial infarction and urinary retention are often experienced as 'sickening'). Nausea generated in the VC is typically episodic and often exacerbated by sights, smells, movement, etc.

There are several neurotransmitters thought to be important here, including serotonin $\left(5-\mathrm{HT}_{2}\right)$, histamine $\left(\mathrm{H}_{1}\right)$, and acetylcholine $\left(\mathrm{Ach}_{\mathrm{m}}\right)$.

3. I feel hungry and I still enjoy my food.The thing is, after only a few mouthfuls I feel full, stuffed, like it is sitting like a heavy weight in my stomach. And then I feel a bit sick and, whoops, up it comes, and I feel better and I'm ready to eat again.

This history suggests a more 'mechanical' cause of nausea and vomiting-classically, gastric squash (for example, secondary to massive hepatomegaly), but also typical of delayed gastric emptying (usually iatrogenic anticholinergic side-effects). It is common in constipation, when biofeedback from a distended colon inhibits gastric emptying.

Serotonin $\left(5-\mathrm{HT}_{4}\right)$ is prokinetic, whereas dopamine slows gut transit.

\section{MANAGEMENT}

\section{Non drug}

Anxiety will often exacerbate nausea. Relaxation techniques may be useful. Avoiding unpleasant odours is important. Odour from wounds or necrotic tumour can be particularly distressing. Antibiotics may be required. Charcoal- or silver-based dressings can help and aromatherapy oils may mask the smell.

Encouraging care givers to prepare and present small quantities at meal times (rather than large amounts of stodgy food 'to build him up') can reduce mealrelated nausea.

\section{DRUGS: FOUR MAIN PALLIATIVE ANTI- EMETICS}

\section{Haloperidol}

Haloperidol is a potent dopamine antagonist which has an effect in the CTZ. Anti-emetic doses (0.5-5 $\mathrm{mg} / 24 \mathrm{~h}$ ) are typically much smaller than antipsychotic doses. It can be administered orally or subcutaneously (bolus or continuous infusion). Typically a patient will only need to use haloperidol for nausea for a few days; until the underlying cause has been treated or the patient succumbs (uraemia, hypercalcaemia, etc.). Dystonic reactions may occur, but are uncommon at these low doses, even with prolonged treatment.

\section{Cyclizine}

Cyclizine blocks acetylcholine (muscarinic) and histamine receptors, so works primarily in the VC. The usual daily dose is $50 \mathrm{mg}$ three times per day orally or $150 \mathrm{mg}$ subcutaneously by continuous infusion. Anticholinergic side-effects can occur and, more rarely, sedation or agitation.

\section{Levomepromazine}

This is a broad-spectrum anti-emetic with wide-ranging effects in the CTZ and VC. The usual anti-emetic dose ranges from 2.5 to $25 \mathrm{mg} / 24 \mathrm{~h}$. If given orally it is typically given as a once daily dose at night. It can also be given subcutaneously (bolus or continuous infusion). It can be very sedative; however this is less of a problem at the lower end of the dose range.

\section{Metoclopramide}

Metoclopramide is a $5-\mathrm{HT}_{4}$ agonist and dopamine antagonist. It acts as a prokinetic in the stomach and proximal small bowel and has some central action in the CTZ. The usual dose range is $30-60 \mathrm{mg} / 24 \mathrm{~h}$ either orally ( $10-20 \mathrm{mg}$ three times per day) or via continuous subcutaneous infusion. Dystonic reactions are uncommon but serious. Colic may be worsened (see Bowel obstruction below). Recent Medicines and Healthcare Products Regulatory Agency guidance seeking to limit the use of metoclopramide did not cover its use in palliative care situations. Clearly, as with all medications, using the lowest effective dose for the shortest possible time is best clinical practice.

In the patient with advanced life-limiting illness who has severe or multifactorial nausea, a combination of levomepromazine and metoclopramide may be particularly useful, providing central and peripheral anti-emesis.

\section{DRUGS: OTHER}

\section{5- $\mathrm{HT}_{3}$ antagonists}

Ondansetron, granisetron, etc. block peripheral and central $5-\mathrm{HT}_{3}$ receptors. They are invaluable in situations characterised by massive $5 \mathrm{HT}_{3}$ release, including chemotherapy, radiotherapy to midline structures, bowel surgery, and some gastrointestinal tumours. They are generally not useful for the palliation of other causes of nausea and tend to cause constipation (which is one of the most common underlying causes of nausea in debilitated patients). 


\section{Prochlorperazine}

Prochlorperazine has a moderate effect on dopamine and histamine receptors. It cannot be given subcutaneously, which limits its use in palliative care. The buccal preparation is absorbed directly into the systemic circulation so can be effective and useful, particularly in out-of-hospital care environments.

\section{Domperidone}

Domperidone is an alternative to metoclopramide. It is slightly less effective, with its prokinetic action limited to the stomach, and no central anti-emetic effects. Its lack of central side-effects does mean it can be used when metoclopramide is not tolerated, e.g. in Parkinson's disease. Domperidone's utility in palliative care is reduced by the lack of a parenteral formulation.

\section{Corticosteroids}

Corticosteroids are useful in specific circumstances, e.g. nausea associated with raised intracranial pressure or reducing tumour-associated oedema causing extrinsic compression of the gut. It can also have a non-specific anti-emetic effect, so can be used as an 'adjuvant' to more standard treatments. Routine use for nausea should be avoided as any beneficial effect tends to be short-lived and medium-term side-effects are almost guaranteed.

\section{Benzodiazepines}

Benzodiazepines can be useful as short-term adjuvants for nausea associated with significant anxiety. Classically this would include anticipatory nausea, e.g. prechemotherapy.

\section{Aprepitant}

This is a substance $P$ antagonist which acts on neurokinin-I receptors. It is expensive and its role in palliative care is not yet clear so it is not recommended for routine use.

TABLE I The palliative management of nausea

\begin{tabular}{|c|c|c|c|}
\hline Type of nausea & $\begin{array}{c}\text { Examples of possible } \\
\text { causes }\end{array}$ & $\begin{array}{l}\text { Treatment for underlying } \\
\text { cause if possible and } \\
\text { appropriate }\end{array}$ & Palliative anti-emetic \\
\hline Constant nausea & $\begin{array}{l}\text { Hypercalcaemia } \\
\text { Uraemia } \\
\text { Septicaemia } \\
\text { Drug toxicity } \\
\text { Opioid }\end{array}$ & $\begin{array}{l}\text { Biphosphonates } \\
\text { ?Hydration } \\
\text { ?Dialysis } \\
\text { Antibiotics } \\
\text { Stop/reduce offending drug } \\
\text { Usually self limiting so } \\
\text { continue opioid }\end{array}$ & $\begin{array}{l}\text { First line: haloperidol }(0.5-5 \mathrm{mg} / 24 \mathrm{~h}) \\
\text { Second line: levomepromazine }(2.5-25 \\
\mathrm{mg} / 24 \mathrm{~h})\end{array}$ \\
\hline $\begin{array}{l}\text { Intermittent, } \\
\text { sights, smells, etc. }\end{array}$ & $\begin{array}{l}\text { Anxiety (e.g. anticipatory } \\
\text { nausea) } \\
\text { Smells (e.g. necrotic wound) } \\
\text { Movement (e.g. vestibulitis) } \\
\text { Raised intracranial pressure }\end{array}$ & $\begin{array}{l}\text { Benzodiazepine } \\
\text { ?Relaxation techniques } \\
\text { ??Acupuncture/hypnotherapy } \\
\text { Antibiotics } \\
\text { Well-ventilated room } \\
\text { Aromatherapy oil in } \\
\text { superficial dressings } \\
\text { Avoid movement } \\
\text { Steroids }\end{array}$ & $\begin{array}{l}\text { First line: cyclizine (150 mg/24h) } \\
\text { Second line: levomepromazine }(2.5-25 \\
\mathrm{mg} / 24 \mathrm{~h})\end{array}$ \\
\hline $\begin{array}{l}\text { After food, made } \\
\text { better by vomiting }\end{array}$ & $\begin{array}{l}\text { Gastric squash } \\
\text { Delayed gastric emptying } \\
\text { Constipation }\end{array}$ & $\begin{array}{l}\text { ?Steroids } \\
\text { Reduce/stop anticholinergic } \\
\text { drugs } \\
\text { Laxatives (combination of } \\
\text { softener and stimulant often } \\
\text { required) }\end{array}$ & Metoclopramide (30-60 mg/24h) \\
\hline
\end{tabular}


Hyoscine hydrobromide (patches)

Hyoscine hydrobromide is an antimuscarinic with a central anti-emetic effect via the vomiting centre. It can be used for motion sickness and in palliative care is often prescribed for excessive drooling (for example in degenerative neurological conditions) and for respiratory secretions at the end of life (the 'death rattle'). Adverse effects, including sedation, delirium, dry mouth, constipation, and urinary retention, limit its wider use as an anti-emetic.

Types of nausea and approaches to management and treatment are summarised in Table I.

\section{SUMMARY}

If nausea or vomiting is not improving consider the following:

- Have you identified the underlying cause?

» Can you treat the underlying cause?

$\checkmark$ remember there may be multiple causes

- Are you using:

" the right drug?

$\diamond \quad$ may need more than one drug or a 'broad spectrum' anti-emetic

» an adequate dose?

$» \quad$ an appropriate route?

$\diamond \quad$ you may need to consider non-oral routes of administration (e.g. subcutaneous, buccal)

\section{BOWEL OBSTRUCTION}

\section{Background}

Malignant bowel obstruction is most commonly caused by ovarian or colorectal cancers. It is a marker of poor prognosis. Complete obstruction is often preceded by episodes of subacute obstruction.

\section{History}

Bowel obstruction is characterised by intermittent nausea associated with abdominal cramps and altered bowel habit. The nausea is relieved by vomiting that may become large in volume and bilious or faeculent.

\section{Investigation}

The diagnosis can often be made based on the history alone. However, as the most effective symptom control is achieved through treating the underlying cause (if possible and appropriate), investigations may be indicated to confirm the cause of the obstruction (important differential diagnoses could include faecal impaction, sigmoid volvulus, obstruction secondary to adhesions) and whether the obstruction is at one level only, or multi-level.
TABLE 2 Multidisciplinary team and treatment roles

\begin{tabular}{|c|l|}
\hline $\begin{array}{c}\text { Multidisciplinary team } \\
\text { role }\end{array}$ & \multicolumn{1}{|c|}{$\begin{array}{c}\text { Treatment } \\
\text { responsibilities }\end{array}$} \\
\hline Oncology & $\begin{array}{l}\text { Chemotherapy } \\
\text { Radiotherapy }\end{array}$ \\
\hline Surgery & $\begin{array}{l}\text { Tumour resection } \\
\text { Defunctioning colostomy/ } \\
\text { ileostomy }\end{array}$ \\
\hline Interventional radiology & $\begin{array}{l}\text { Stenting } \\
\text { Venting gastrostomy }\end{array}$ \\
\hline Dietician & $\begin{array}{l}\text { Low residue diet } \\
\text { ?Elemental diet }\end{array}$ \\
\hline
\end{tabular}

TABLE 3 Management of malignant bowel obstruction

\begin{tabular}{|c|c|}
\hline Subacute obstruction & Complete obstruction \\
\hline Dexamethasone & (Dexamethasone) \\
\hline Metoclopramide & Hyoscine butylbromide \\
\hline Softening laxative & Octreotide \\
\hline (Octreotide) & \\
\hline
\end{tabular}

\section{Treatment}

This requires very close co-operation between the members of the multidisciplinary team (see Table 2) and will depend on the type of malignancy, the extent of any peritoneal disease, whether the obstruction is single or multi-level, the patient's functional status, etc.

If treatment to relieve the obstruction (surgical excision, stenting, chemo/radiotherapy) is not possible or appropriate, then 'conservative' palliative symptom management is required. This aims to facilitate resolution of episodes of sub-acute obstruction and subsequently to ameliorate the symptoms associated with complete obstruction.

\section{CONSERVATIVE MANAGEMENT OF MALIGNANT BOWEL OBSTRUCTION}

This is summarised in Table 3.

\section{Dexamethasone}

A course of high-dose steroids (e.g. dexamethasone 8 $\mathrm{mg}$ daily subcutaneous bolus for 5 days) may help to reduce peri-tumour and bowel wall oedema and promote resolution of an episode of subacute bowel obstruction.

\section{Metoclopramide}

Improved intestinal motility can improve passage of gut contents across an area of partial obstruction. Typical 
metoclopramide doses would range from $30-60 \mathrm{mg}$ by subcutaneous infusion over 24 hours. Metoclopramide should be used with caution in the presence of a history of colic and should be stopped immediately if colic worsens. This may indicate the patient has developed complete bowel obstruction and is now at increased risk of bowel perforation.

\section{Softening laxative}

Obviously keeping bowel contents soft will allow easier passage across areas of partial obstruction.

\section{Hyoscine butylbromide}

This is an effective antispasmodic which can relieve colic. Typical dose range is $60-120 \mathrm{mg}$ subcutaneous infusion over 24 hours. It should be avoided in subacute obstruction as it will delay or prevent the spontaneous resolution of an episode.

\section{Octreotide}

Octreotide is a somatostatin analogue. It has a number of effects on bowel physiology. Of particular interest for the management of bowel obstruction is the fact that octreotide dramatically reduces the volume of gastrointestinal secretions, reduces bowel wall oedema, and may even have a direct anti-tumour effect. It is most frequently used in complete bowel obstruction to reduce the volume and frequency of vomiting, but may also have a role in promoting the resolution of episodes of subacute obstruction. A typical dose would be $500 \mu \mathrm{g}$ over 24 hours via subcutaneous infusion.

\section{WHAT ABOUT 'DRIP AND SUCK'?}

Traditionally, conservative management has consisted of the insertion of a wide bore nasogastric tube for drainage of gastric contents and hydration with intravenous fluids. However the nasogastric tube is unpleasant, unsightly, and often poorly tolerated, whilst hydration can cause increased gastrointestinal secretions and worsening of symptoms. Venting gastrostomy is a better tolerated alternative if the medical treatments given above fail to provide acceptable reductions in vomiting volume and frequency.

\section{HIGHLIGHTS}

- The best symptom control is achieved by treating the underlying cause of that symptom, if possible and appropriate.

- The three types of nausea can indicate different underlying causes and help guide choice of the appropriate palliative anti-emetic.

- Oral drugs (including oral anti-emetics) may not be effective in the presence of nausea.

- Constipation is a very common cause of nausea in patients at the end of life.

- The effective management of malignant bowel obstruction requires a multidisciplinary team approach.

\section{Further reading}

Where you will discover that the palliative management of nausea and vomiting is based almost entirely on expert opinion!

I Davis MP, Hallerberg G, Palliative Medicine Study Group of the Multinational Association of Supportive Care in Cancer. A systematic review of the treatment of nausea and/or vomiting in cancer unrelated to chemotherapy or radiation.J Pain Symptom Manage 2010; 39: 756-67. http:// dx.doi.org/ I0.1016/j.jpainsymman.2009.08.010

2 Glare P, Miller J, Nikolova T,Tickoo R. Treating nausea and vomiting in palliative care: a review. Clin Interv Aging 20I I; 6: 243-59. http://dx.doi. org/I0.2I47/CIA.SI3I09

3 Twycross R,Wilcock A (eds). Palliative Care Formulary. 4th edn. Nottingham: Palliativedrugs.com Limited, 20I I. http://www.palliativedrugs.com/ palliative-care-formulary.html 


\section{SELF-ASSESSMENT QUESTIONS}

I. Which ONE of the following physiological changes is associated with the sensation of nausea?
A. Lower oesophageal sphincter contraction.
B. Gastric hypermotility.
C. Lower intragastric $\mathrm{pH}$ levels.
D. Small bowel retroperistalsis.
E. Enhanced gastrocolic reflex.

2. A 65-year-old woman with metastatic breast cancer presents with fatigue and constant nausea.

Bloods reveal:

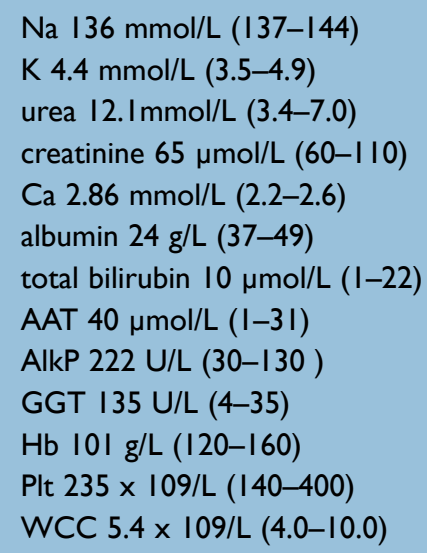

Which anti-emetic would you choose?
A. Ondansetron.
B. Haloperidol.
C. Levomepromazine.
D. Metoclopramide.
E. Cyclizine.

3. A 45-year-old man has locally recurrent squamous cell cancer of the oropharynx. He has trismus and halitosis. Oral care is very difficult because of his limited mouth opening, and because it causes him to feel nauseated. He also describes nausea when he smells coffee, which used to be his favourite drink.

Which anti-emetic would you choose:
A. Ondansetron.
B. Levomepromazine.
C. Cyclizine.
D. Metoclopramide.
E. Haloperidol.

4. A 74-year-old woman with end-stage renal failure is in the terminal phase of her illness. She is deteriorating daily and is now bed-bound with minimal oral intake. She has a chest infection and is bringing up foul-smelling sputum. She is able to tell you that the worst thing she is experiencing is nausea.

Which ONE anti-emetic would best cover all causes of this patient's nausea?
A. Levomepromazine.
B. Cyclizine.
C. Metoclopramide.
D. Ondansetron.
E. Haloperidol.

5. A 54-year-old woman with metastatic ovarian cancer develops bowel obstruction. Investigations reveal widespread peritoneal disease with multiple levels of obstruction. She continues to have distressing large volume vomits despite 'optimal' medical treatment (steroids, octreotide, buscopan).

Which ONE of the following would be indicated now?
A.Wide-bore nasogastric tube.
B. Small bowel stent insertion.
C. Radiotherapy.
D. Venting gastrostomy.
E. Defunctioning ileostomy.

This paper was originally published as part of the Palliative Care module on the RCPE Online Education Portal. Specialty Modules for continuing medical education, including the answers to these questions, are available to Fellows and Members at http://learning.rcpe.ac.uk 